\title{
THERMAL PROFILE EVALUATION IN PROXIMAL TIBIAL SHAFT PSEUDARTHROSIS DIAGNOSIS - A CASE STUDY
}

\author{
Wally auf der Strasse*, Daniel Prado Campos*, Celso J. Aguiar Mendonça*, Joaquim Mendes**

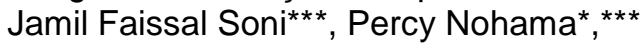 \\ * Federal Technological University of Paraná, 3165, Av. Sete de Setembro, Curitiba/Paraná, Brasil. \\ wallystrasse@hotmail.com \\ ** Faculty of Engineering University of Porto, Rua Dr. Roberto Frias, 4200-465, Porto, Portugal. \\ igabriel@fe.up.pt \\ *** Pontifical Catholic University of Paraná, Rua Imaculada Conceição, 1155, Curitiba/Paraná, Brasil. \\ percy.nohama@gmailcom
}

\begin{abstract}
Pseudarthrosis, also known as nonunion, is a serious pathology in bone fractures that present a fault in the healing process. This article presents the thermal analyses of a male patient with a tibia fracture stabilized by a circular (llizarov) external fixator. The thermal images were capture along the tibia length, outside and in-between the insertion rings. Significant temperature differences were observed between the three sections of the tibia: the central zone medial tibial $\left(25.9^{\circ} \mathrm{C}\right)$, between the second and the third ring $\left(26.5^{\circ} \mathrm{C}\right)$ and the proximal tibia between the third and fourth external fixator ring $\left(25.2^{\circ} \mathrm{C}\right)$. The obtained results indicate that thermography might help in the diagnosis and follow up of pseudarthrosis of tibial shaft. The metabolic and vascular alterations at the fracture site encompasses the bone healing process, formation and remodelling produce skin temperature changes that can be monitored by thermography.
\end{abstract}

\section{Introduction}

Tibial shaft fractures are the most frequent among long bone fractures, mainly affecting young males aged 21 to 30 years old [1]. An important critical aspect in orthopaedics / traumatology is the follow-up of the clinical evolution of the nonunion (pseudarthrosis) consolidation process of long bone diaphyseal fractures (tibia, femur and humerus) [2].

The use of external fixators, like the circular Ilizarov and variants, have demonstrated efficacy in dealing with the fracture healing and bone elongation deformities. One of the main complications observed, is the discrepancy of lower limb lengths, requiring differentiate approaches to minimize residual treatment refractoriness.

The aim of this study was to investigate the temperature differences that occur at the proximal portion of the tibial pseudarthrosis site in an adult male patient treated with llizarov's circular fixator.

\section{Methods}

The study complied the ethical recommendations stated on Resolution 466/12 - Ministry of Health - and was approved by the Research Ethics Committee at the Federal Technological University of Paraná (UTFPR), letter of approval number 3014748. Also, it was approved by the Research Ethics Committee at the Clinical Hospital of the Federal University of Paraná (HC/UFPR) according to the letter of approval number 3067005. The sample consisted of a 34 years old male patient.

Anteroposterior (AP) thermal images were acquired, with the patient lying supine (LS). It was used a medical grade thermal camera, model T530 (FLIR® Systems Inc., Wilsonville, Oregon, USA) fixed on a specific support for capturing images perpendicularly to the Region Of Interest (ROI). The distance between the volunteer and the camera was set to $0.40 \mathrm{~m}$, while the patient remained in supine position lying on the clinical table. The camera main features are: NETD $<30 \mathrm{mK}$, and the sensor array size of $320 \times 240$ pixels, with an accuracy of $\pm 2 \%$ of the reading. Thermal mapping and image interpretation was performed using ThermaCAM Researcher Pro 2.9 and Flir Tools 6.4 software.

The image data were also processed in MATLAB ${ }^{2} 2017$ a (Mathworks, USA); first the images were converted to grayscale level, then filtered for noise elimination, edge detection and image segmentation of the regions of interest. The results presentation includes histogram, the average temperature values of the ROls, temperature surface threedimensional (3D) graphs and temperature dispersion boxplot of the median, $25^{\text {th }}$ and $75^{\text {th }}$ percentile scores.

\section{Results and Discussion}

The thermal profile of the tibia shows an average temperature of the total tibial shaft between the three sections of the tibia: the central zone - medial tibial $\left(25.9^{\circ} \mathrm{C}\right)$, between the second and the third ring $\left(26.5^{\circ} \mathrm{C}\right)$ and the proximal tibia between the third and fourth external fixator ring $\left(25.2^{\circ} \mathrm{C}\right)$, as shown in Figure 1 . The tibia was divided in 10 portions 
of 10 pixels between $0-100$, being 0 the proximal and 100 the distal, and the $Y Y$ axis $(0-120)$ represents the transverse distance of the analysed limb.
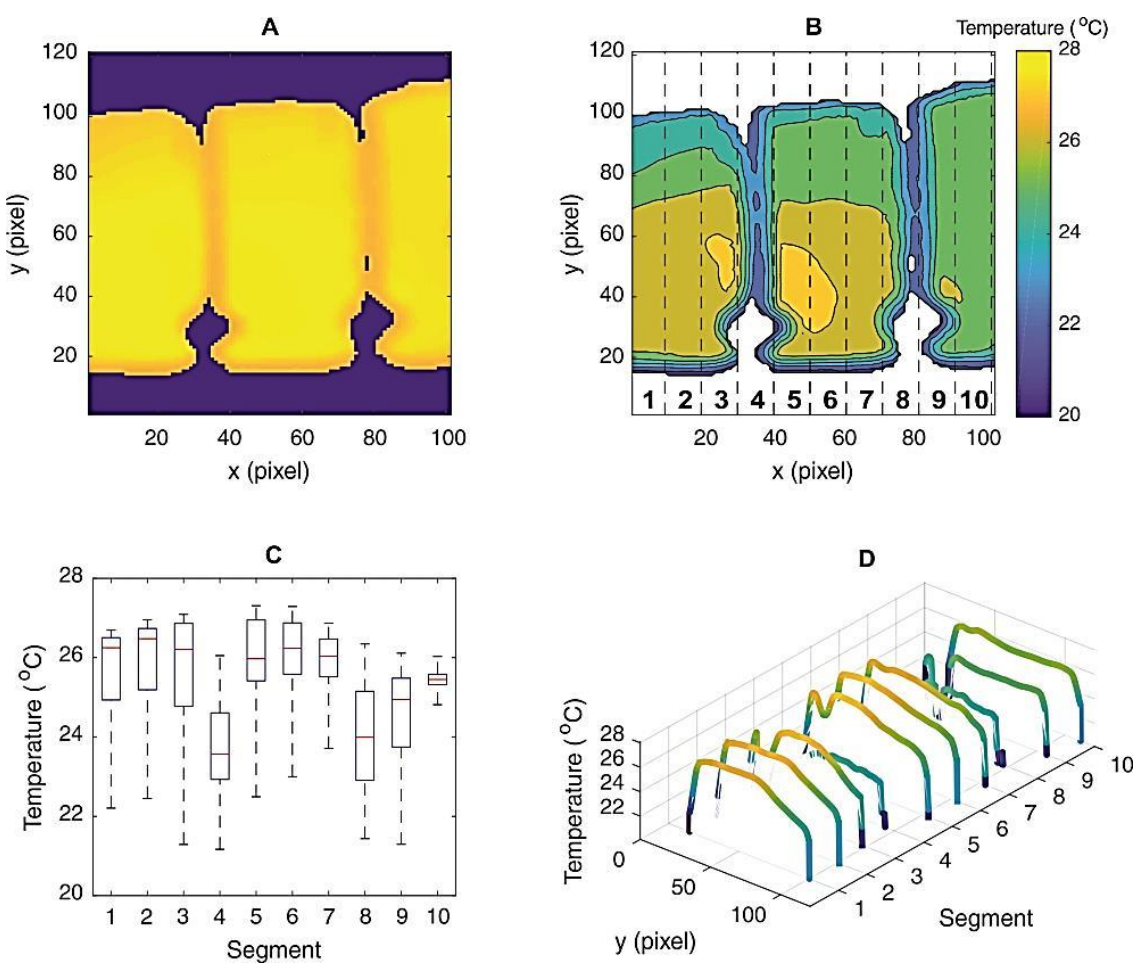

Figure 1: Infrared image of right lower limb tibia in Lying Supine (LS) in an anteroposterior (AP). $A-$ Thermal image of the tibia after segmentation; $B$ - Similar temperatures areas; $C$ - median temperature of each portion of the tibia analysed; $D$ - Average of the temperature in each portion of the area analysed.

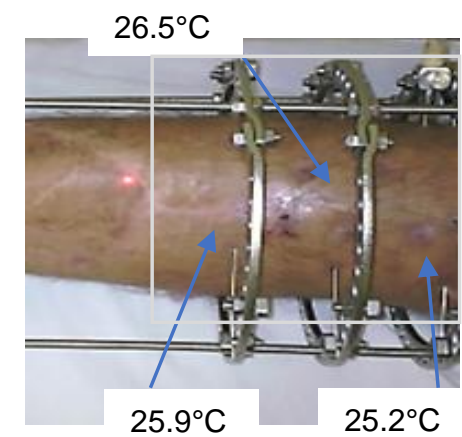

Figure 2: Picture of tibia and the analysed area (white rectangle).

Regarding the use of Ilisarov external fixator, there is a single clinical study that describes a thermographic monitoring of Ilizarov external fixator bone stretching. Moravisiewicz et al. [3] investigated 13 patients who were submitted to tibial bone stretching, and weekly examined by X-ray and medical thermography.

The researchers state that the thermography is an excellent technology to examining the thermal processes, as well as, tissues located directly under the dermis, such as tibial bone tissue [4-5]. Thus, it was observed that the temperature differences in the bone lengthening process compared to the symmetrical contralateral limb temperature may indicate that the proposed lengthening (stretching) was very fast in some cases, or in opposition, the osteogenesis process was disturbed or even interrupted. Regarding the patients studied, nine cases presented disturbances in healing, suggesting interruption in bone regeneration. Values between 0.2 and $0.9^{\circ} \mathrm{C}$ indicated interrupted regeneration 
and values above $1.0^{\circ} \mathrm{C}$ indicated bone regeneration compared to radiographs. The results presented in [3] show temperature differences from the use of llisarov external fixator, corroborating the results obtained.

The thermal profile of the tibia shows an average temperature of the medial region of the tibia of $25.9^{\circ} \mathrm{C}$, lower than the proximal region of the tibia, where the average temperature obtained was $26.5^{\circ} \mathrm{C}$ between the second and third ring of the fixing circular (llisarov) and the portion of the proximal tibia between the third and fourth ring of the circular fixator (Ilisarov) adjacent to the tibial tuberosity line showed a temperature of $25.2^{\circ} \mathrm{C}$.

In the present study, a decrease of $1.3^{\circ} \mathrm{C}$ was also observed between the fixator rings (llisarov), in the proximal region of the tibia corresponding to the site of bone non-union (pseudoarthrosis). In comparison with the average temperature of the entire medial region of the tibia evaluated, where the temperature presented was $26.5^{\circ} \mathrm{C}$, an increase of $0.6^{\circ} \mathrm{C}$ was observed, considered normal, because according to [6] proximal region has higher temperatures in healthy people, with an average of $31.1^{\circ} \mathrm{C}$. However, the region corresponding to the tibial tuberosity showed a decrease in temperature compared to the values obtained between the second and third bone fixation rings, these data may suggest that, in the region adjacent to the tibial tuberosity the bone healing process may be showing an interruption of bone healing. These values presented showed focal metabolic changes in the specific proximal region of the analysed tibial. An increase (or decrease) in temperature during the bone healing process with the llizarov technique is associated with vascular changes at the fracture site and metabolic changes related to bone regeneration and remodeling stages [3].

\section{Conclusions}

Monitoring a fracture of the tibial axis using thermography is a convenient way to monitor the healing process. Although, based on a single case, the results clearly show a decrease in temperature in the region corresponding to the bone non-union, between the insertion rings of the circular external fixator (llizarov). This decrease in skin temperature may be related to local bone metabolism, providing additional information on clinical diagnosis, valuable for further treatment adjustment.

\section{REFERENCES}

[1] De Azevedo Filho F. A. S., et al., Reliability of the radiographic union scale in tibial fractures (RUST), Revista Brasileira de Ortopedia. - Vol. 52, no 1 (2017), pp. 35-39, 2017.

[2] Leow J. M., et al., The radiographic union scale in tibial (RUST) fractures. Bone and Joint Research; 5(4): pp. $116-121,2016$

[3] Morasiewicz L., et al. Use of thermography to monitor the bone regenerate during limb lengthening--preliminary communication, Ortopedia, traumatologia, reabilitação. - Vol. 10, no 3 (2008), pp. 279-285, 2008.

[4] Albert S. M., Glickman M., Kallish M. Thermography in orthopedics, Annals of the New York Academy of Sciences. - Vol. 121, no. 1 (1964), pp. 157-170, 1964.

[5] Wasilewski K., Deboa D. E., Królewski J. Exame termográfico do quadril e da epífise distal do fêmur em crianças após a cirurgia do fêmur proximal, Chirurgia narzadow ruchu i ortopedia polska. - Vol. 60, no 3 (1995), pp. 181-185, 1995.

[6] Brioschi, M. L., Teixeira, M. J., Yeng, L. T., \& Silva, F. M. R. M. Manual de termografia médica, 2012. 